\title{
THE INVESTIGATION OF NATURAL-RUBBER FOR IMPROVING SELF-POWERED HEAT DETECTOR BASED ON THERMOELECTRIC GENERATORS
}

\author{
Krittanon Prathepha \\ Department of Electrical Engineering ${ }^{l}$ \\ Worawat Sa-ngiamvibool $\bowtie$ \\ Department of Electrical Engineering ${ }^{l}$ \\ wor.nui@gmail.com \\ ${ }^{1}$ Mahasarakham University \\ Main Road, Maha Sarakham province, Thailand, 44150
}

$\triangle$ Correponding author

\begin{abstract}
Fire hazard has destroyed humanity creations. Fire detectors have been developed by using different techniques. Thermoelectric generator (TEG) is a part of energy harvesting which is able to convert heat into electricity because of temperature difference between hot and cold side of thermoelectric device (TE). Different materials are used for thermoelectric generators which depend on the characteristics of the heat source, heat sink and the design of the thermoelectric generator. Many thermoelectric generator materials are currently undergoing research. This paper presented an investigation of seeking an alternative way of detecting fire hazard by developing architecture prototype of a fire detection technique using natural rubber. The thermoelectric prototype used self-powered device which improved the temperature difference gap and stabilized the cold side of TE alongside natural rubber as the cooling material. The technique is relatively simple system realization based on three viable components, i.e. a heat sensor, a low-power RF-transmitter and a RF-receiver. The heat sensor is designed and fabricated by thermoelectric and heat sink with natural rubber (NR) coating. The NR coating is heat absorption reduction. Therefore, the temperature difference is wildly resulting in the higher TE output voltage. The voltage is also supplied to the low-power RF transmitter module. In case of fire hazard, the temperature increases from 26 to $100{ }^{\circ} \mathrm{C}$, the prototype can operate successfully. This technique will solve potentially the power supply issue in fluctuated situations. The rubber coating from rubber trees in Thailand would be a value chain added for bio-economy, supporting a sustainable development goal of the country.

Keywords: heat detector, natural-rubber, self-powered, thermoelectric, RF-transmitter, RF-receiver, fire hazard, heat absorption, heat sensor, heat sink.
\end{abstract}

DOI: $10.21303 / 2461-4262.2021 .002117$

\section{Introduction}

In history, fire hazard has destroyed humanity creations and becomes even more danger at the present time due to global warming crisis. Generally, there are two methods of fire detection which using heat and smoke detectors [1]. These devices are very effective for fire detection. However, in unfortunate situation such as losing electricity, poor installation and short circuit will cause them to malfunction. Therefore, alternative energy increasingly becomes a popular in developing electronic devices afterwards. Thermoelectrical energy harvesting is the one of the techniques that extends over many researches [2-4]. Temperature sensor is employed in many applications such as in heat detector [1] for fire hazard or smoke detector for global warming crisis. Typically, these sensors are very effective for fire detection. However, in fluctuated situation such as losing electricity, poor installation and short circuit will cause them to malfunction. As commercially available heat detectors are bulky and consume more external power to drive the electronic devices and temperature sensor, the need for possible self-powered detector for fully viable temperature sensor system has increasingly been motivated [5-8].

Unfortunately, attempts at possible powered sensors without external power supply have particularly been demonstrated based on, for example, the energy conversion techniques [9-12], and the surface acoustic wave (SAW) techniques $[13,14]$. The energy conversion techniques convert 
other kinds of energy to electrical power, such as ultraviolet rays [7, 8], heats [11], vibrations [13], and electromagnetic waves [15]. Whilst, the surface acoustic wave (SAW) techniques are passive sensors. Such techniques have, however, repeatedly suffered from low power, needed the extra power to drive the sensor system and limited mobility. In addition, SAW technique is undesirable for wireless sensor. Since, SAW techniques based on passive sensor approaches [14] have particularly limited a low frequency signal and low self-powered, which have particularly been inversely proportional to the propagation in several meters.

Recently, a self-powered sensor has particularly been demonstrated for wireless temperature sensor based on thermoelectric (TE) module [11]. Where, TE modules are used as both power module and sense module in a self-powered wireless temperature sensor. Such techniques have, however, repeatedly suffered from low generated power and limited the operating time. Theoretically, thermoelectric generator (TEG) is the part of energy harvesting which is able to convert heat into electricity because if there is a temperature difference between hot and cold side of thermoelectric device (TE), it will potentially generate electric power. Recently, the heat pipe technique is applied to suppressing heat leakage at the cold side of TE in order to increase output power [2]. The heat pipe technique was desirable effectiveness in terms of suppressed heat and increased output voltage, although increasing number of heat pipes slightly reduced output power. But the autonomous maximum power point is presented for harvesting maximum TEG energy [3, 4]. This point is slightly increased output power and considered to be unsuitable for implementation. In term of suppressed heat, paraffin has particularity been demonstrated for heat absorption of temperature sensor based on TEG [11]. However, as paraffin is the product of petrochemical industry. When the solid paraffin reaches a certain temperature, the melt paraffin causes the heat absorption reduction. On the other hand, rubber mainly becomes popular in various commercial and residential applications. Especially, the natural rubber (NR) has excellent thermal conductivity and insulation properties, which was preferred for electronics [16, 17]. Moreover, the NR can be extended the life of electronic products that operating at high temperature for long-term stability by enhancing the mechanical properties of silicone rubber composite [17].

Due to the limitation in some researches, this research proposes another fire detection technique using self-powered device which improved the temperature difference gap and stabilized the cold side of TE. The device comprises a TE which used as the generator alongside Thai rubber as the cooling material. Thai rubber is a natural material which has thermal conductivity slightly different compared to a paraffin. Moreover, it is a solution for the rubber in Thailand.

\section{Materials and methods}

The concept of thermoelectric (TE) is shown in Fig. 1. It consists of hot and cold side where the temperature is applied. TE is semiconductor materials which are p-type and n-type semiconductors. Also, at the end of each junction connects to electrical conductor for the current flowing. Thermoelectric generator (TEG) is simply explained by Fig. 1, a. When the heat is applied on the hot side of TE, it causes a temperature difference between hot and cold side. Electricity is started generating because of the electron flowing inside semiconductor materials consecutively. This phenomenon is known as Seebeck effect. To increase the voltage, multiple semiconductors are formed to be a module by connecting $\mathrm{p}$ - and $\mathrm{n}$ - junction to each other as shown in Fig. 1, $\boldsymbol{b}$. The open circuit voltage can be determined in equation:

$$
V_{\text {out }}=\alpha \Delta T
$$

where $\alpha$ and $\Delta T$ are the Seebeck coefficient and the temperature difference between hot and cold side of TE, respectively. Fig. 1 despites an internal resistance inside the TE module. The output voltage can be approximated as the open circuit voltage when connecting to the load which has much times higher resistance than internal resistance of TE [11].

Rubber mainly becomes popular in various commercial and residential applications. Commonly, they are two types of rubbers which are natural rubber (NR) and silicone rubber (SiR). Mostly, they are considered to be electrical and thermal insulator because they have excellent 
thermal conductivity and insulation properties, was preferred for electronics. [16] have used molecular dynamics simulation to calculate the value of thermal conductivity of NR which resulted in $0.35 \mathrm{~W} \cdot \mathrm{m}^{-1} \cdot \mathrm{K}^{-1}$. [17] have extended the life of electronic products that operating at high temperature for long-term stability by enhancing the mechanical properties of silicone rubber composite using hexagon boron nitride (h-BN). The results show that the thermal conductivity was increased to $0.95 \mathrm{~W} \cdot \mathrm{m}^{-1} \cdot \mathrm{K}^{-1}$ and the volume resistivity reached $2.5 \times 10^{11} \Omega \cdot \mathrm{cm}$.

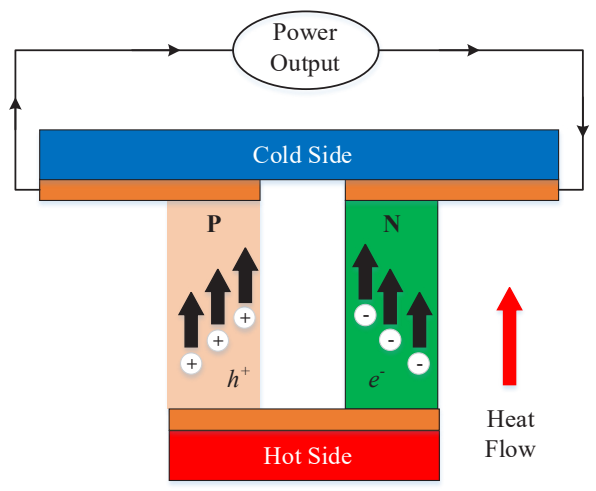

$a$

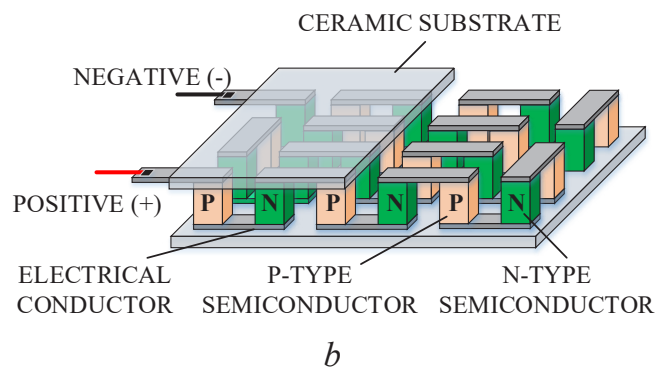

Fig. 1. The main signature: $a$ - seebeck effect; $b$ - thermoelectric module

In this experiment, NR was desperately considered to be the thermal stabilizing between cold and hot side of TE. As fire hazard situation, everything in vicinity increases their temperature. Therefore, NR is an important role for preserving cool by conducting the heat at the cold side while the hot side is a thermal insulator in order to operate the device.

As the limitation, this research is focused on cold-side stabilized material which is Thai rubber. It has high specific heat capacity (about $2.005 \mathrm{~kJ} \cdot \mathrm{kg}^{-1} \cdot \mathrm{K}^{-1}$ ) which is relatively close to solid paraffin. Fig. 2 shows fabricated self-powered sensor. The sensor consists of three components, i.e. a thermoelectric (TE), heat sink and natural-rubber (NR), whilst NR used to coat the heat sink. A TE and heat sink with NR coating compose a self-powered temperature sensor.



Fig. 2. The fabricated self-powered sensor

As mentioned above, the fabricated self-powered sensor as shown in Fig. 2. There will be two main parts to compare the self-powered sensor which one is the differential temperature 
measurement of heat sink with natural rubber coating, the sizes of heat sink are $40 \times 40 \times 18$ and $40 \times 45 \times 21 \mathrm{~mm}$ as shown in Fig. 3 for 6 models that has the difference in number of fins and coating thickness. Another part is the differential temperature measurement of heat sink without the natural rubber coating in Table 1.

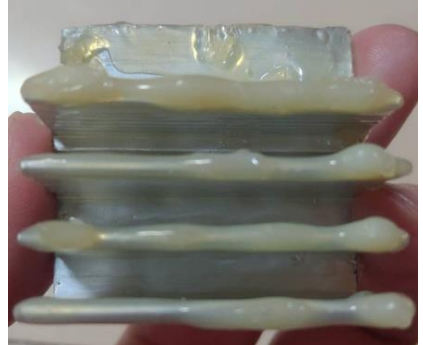



$b$

Fig. 3. The main signature: $a$ - the fabricated heat sink of self-powered sensor with natural rubber coating with-four fins (F4T05-F4T10); $b$ - with-eight fins (F8T05-F8T10)

Table 1

The variety fin and coating-thickness of heat sink for self-powered sensor

\begin{tabular}{cccc}
\hline Model & No. of Fin & Size $(\mathbf{m m})$ & Coating Thickness $(\mathbf{m m})$ \\
\hline F4T00 & & $40 \times 45 \times 21$ & Non-coating \\
F4T05 & 4 & & 0.50 \\
F4T10 & & & 1.00 \\
F8T00 & & $40 \times 40 \times 18$ & Non-coating \\
F8T05 & 8 & & 0.50 \\
F8T10 & & & 1.00
\end{tabular}

Then, the temperature of self-powered sensor with the natural rubber coating of 4 models and without natural rubber coating of 4 models in Table $\mathbf{1}$ are measured by using data acquisition unit (YOKOGAWA DAU-MX100) which the shortest measurement interval time is 500 ms. Fig. 4 shows experimental setup of the fabricated self-powered sensor. The heat source produced heated temperature from $\sim 26^{\circ} \mathrm{C}$ (room temperature) to $100^{\circ} \mathrm{C}$ consistently and running the experiment within 90 seconds.

Fig. 5 shows the proposed simple system realization of a self-powered heat detector based on thermoelectric (TE) generators with natural-rubber (NR) where the system is relatively simple based on three viable components, i.e. a heat sensor, a low-power RF-transmitter and a RF-receiver.



Fig. 4. The measurement temperature value setup 

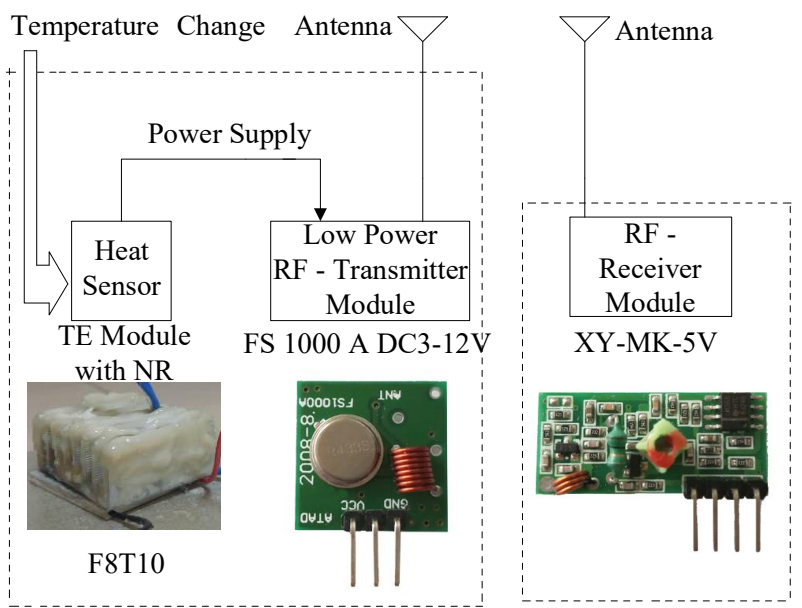

Fig. 5. Proposed system realization of a self-powered heat detector based on thermoelectric generators with natural-rubber (NR)

The heater sensor consists of three components, i.e. a thermoelectric (TE), heat sink and natural-rubber (NR), whilst NR used to coat the heat sink. A TE and heat sink with NR coating compose a self-powered temperature sensor. The function of the TE is to measure the temperature difference between its two sides (i.e., hot and cold side) and to convert the temperature gradient into electric power. Where, this electric power has particularly been proportional to the temperature difference. In case of fire hazard, the NR coating is heat absorption reduction. Therefore, the temperature difference is wildly. When the TE is exposed to a temperature difference, it will generate a thermal voltage which is mathematically related to the temperature difference. This thermal voltage is also supplied to the low-power RF transmitter module (FS100A DC 3-12 V). Therefore, this technique is simple system realization, low-power wireless device and wide temperature difference.

\section{Results and Discussion}

As shown in Fig. 4, for the first part of experiment, the heat source produced heated temperature from $26^{\circ} \mathrm{C}$ (room temperature) to $100{ }^{\circ} \mathrm{C}$ consistently and running the experiment within 90 seconds. To figure out the effectiveness of coated rubber, the relationship of four variables of TE such as hot side temperature $\left(T_{h o t}\right)$, cold side temperature $\left(T_{\text {cold }}\right)$, differential temperature $(\Delta T)$ and output-voltage were considered precisely. Table 2 concludes the experiment results of heat sensors. These heater sensors consist of coating heat sink 6 models and thermoelectric (model TEC12706) generators.

Table 2

Experiments result of heat sensors

\begin{tabular}{ccccccc}
\hline \multirow{2}{*}{ No. Fins } & \multirow{2}{*}{ Model } & \multirow{2}{*}{ Coating Thickness $(\mathbf{m m})$} & \multicolumn{3}{c}{ TE Temperature $\left({ }^{\circ} \mathbf{C}\right)$} & \multirow{2}{*}{ TE output-voltage (V) } \\
\cline { 4 - 6 } & & & $\boldsymbol{T}_{\text {hot }}$ & $\boldsymbol{T}_{\text {cold }}$ & $\boldsymbol{\Delta} \boldsymbol{T}$ & \\
\hline \multirow{2}{*}{4} & F4T00 & - & 49.80 & 37.70 & 18.10 & 0.34 \\
& F4T05 & 0.50 & 52.10 & 32.60 & 19.50 & 0.45 \\
& F4T10 & 1.00 & 59.70 & 29.50 & 30.20 & 0.53 \\
& F8T00 & - & 55.80 & 34.90 & 20.90 & 0.36 \\
& F8T05 & 0.50 & 57.20 & 29.60 & 27.60 & 0.51 \\
& F8T10 & 1.00 & 62.30 & 28.40 & 39.90 & 0.56
\end{tabular}

Table 2 shows that the TE output voltage of heat sensor has particularly been proportional to the number of fins and NR coating thickness. Consequently, the NR coating is heat absorption reduction. Therefore, the temperature difference $(\Delta T)$ is more wildly (from 18.10 to $30.20{ }^{\circ} \mathrm{C} @ 4$-fin 
and from 20.90 to $39.90{ }^{\circ} \mathrm{C}$ @ 8-fin). In this sample, the F8T10 model is the optimal model which is built in the prototype of self-powered heat detector based on thermoelectric generators.

Fig. 6, 7 depict the temperature difference $(\Delta T)$ measurement on the 4-fin heat sinks. As shown in Fig. 6, for the first part of experiment with 3 models in Table 2, firstly, the F4T00 model has the temperature difference $(\Delta T)$ from $0-18.10^{\circ} \mathrm{C}$ and the value of correlation coefficient $\left(R^{2}\right)$ is 0.9863 . Secondly, the F4T05 model has the temperature difference $(\Delta T)$ from $0-19.50{ }^{\circ} \mathrm{C}$ and the value of correlation coefficient $\left(R^{2}\right)$ is 0.9786 . Finally, the F4T10 model has the temperature difference $(\Delta T)$ from $0-30.20^{\circ} \mathrm{C}$ and the value of correlation coefficient $\left(R^{2}\right)$ is 0.9962 . It can be seen that the temperature difference $(\Delta T)$ has particularly been linearity function of time.

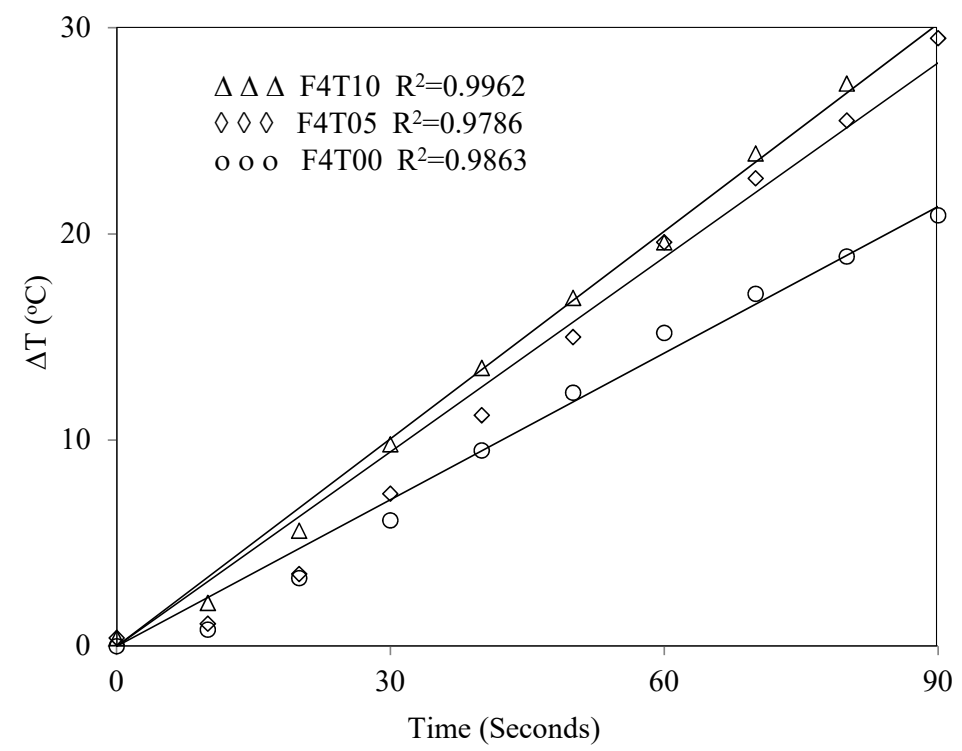

Fig. 6. Experiment results of the temperature difference $(\Delta T)$ measurement on the 4-fin heat sinks (model F4T00, F4T05 and F4T10)



Fig. 7. Experiment results of the temperature difference $(\Delta T)$ measurement on the 8-fin heat sinks (model F8T00, F8T05 and F8T10)

Similarity to experiment results of the temperature difference $(\Delta T)$ measurement on the 4-fin heat sinks, Fig. 6 depicts the temperature difference $(\Delta T)$ measurement on the 8-fin heat sinks. For the experiment with 3 models in Table 2, firstly, the F8T00 model has the 
temperature difference $(\Delta T)$ from $0-20.90{ }^{\circ} \mathrm{C}$ and the value of correlation coefficient $\left(R^{2}\right)$ is 0.9882 . Secondly, the F8T05 model has the temperature difference $(\Delta T)$ from $0-27.60{ }^{\circ} \mathrm{C}$ and the value of correlation coefficient $\left(R^{2}\right)$ is 0.9870 . Finally, the F8T10 model has the temperature difference $(\Delta T)$ from $0-39.90{ }^{\circ} \mathrm{C}$ and the value of correlation coefficient $\left(R^{2}\right)$ is 0.9825 . It can be seen that the temperature difference $(\Delta T)$ has particularly been linearity function of time.

Fig. 8, 9 depict the TE output voltage measurement with the 4-fin heat sinks. It can be seen that the TE output voltages have particularly been proportional to time. And it is unlike existing approaches, when TE output voltage drops with further increase of time.

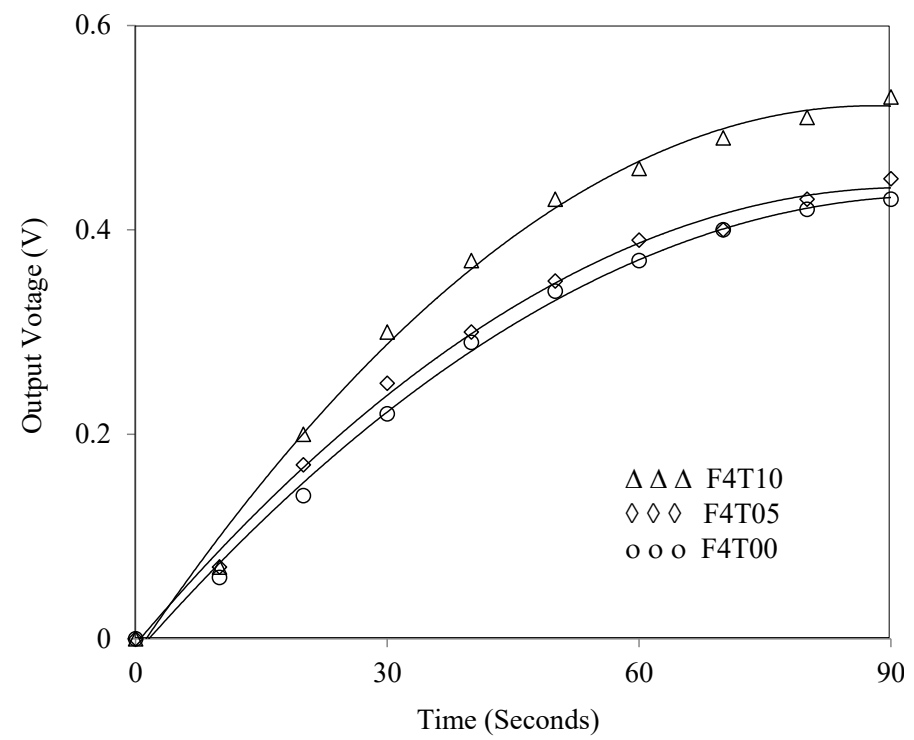

Fig. 8. Experiment results of the TE output voltage measurement with the 4-fin heat sinks (model F4T00, F4T05 and F4T10)

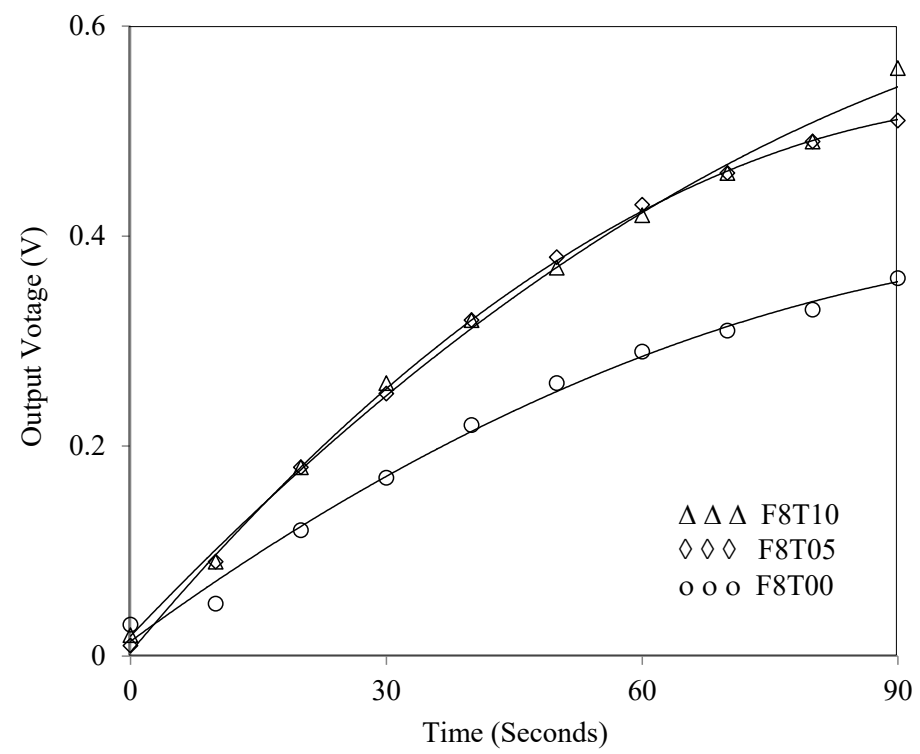

Fig. 9. Experiment results of the TE output voltage measurement with the 8-fin heat sinks (model F8T00, F8T05 and F8T10)

For the second part of experiment, as shown in Fig. 5, the proposed simple system realization of a self-powered heat detector based on thermoelectric (TE) generators with natural-rubber (NR) is implemented. The prototype of this system is shown in Fig. 10. The dimension of 
prototype is $80 \times 80 \times 120 \mathrm{~mm}$. The low-power RF transmitter module (FS100A DC 3-12V) is supplied by 4 heat sensors. In case of fire hazard, the temperature increases from 26 to $100{ }^{\circ} \mathrm{C}$, the prototype can successfully operate.

As mentioned above, natural rubber is used as a material with heat sink. The results showed that temperature difference $(\Delta T)$ significantly when compared between with-coated natural rubber and without-coated natural rubber of both the 4 and 8 fins heat sink models. It was found that the coating with natural rubber model gave higher the temperature difference than that of the other. This result illustrated that natural rubber could be efficiently used in a cold-side stabilized material of the self-powered heat detector. However, the self-powered heat detector required the proper installation as well as commercial product (i.e., smoke and heat detector) which ideally needs to detect the beginning of the fire. Moreover, the device could not be monitored whether it is malfunction or not. Furthermore, these disadvantages should be improved in terms of the crucial fire detection area and the device monitoring.

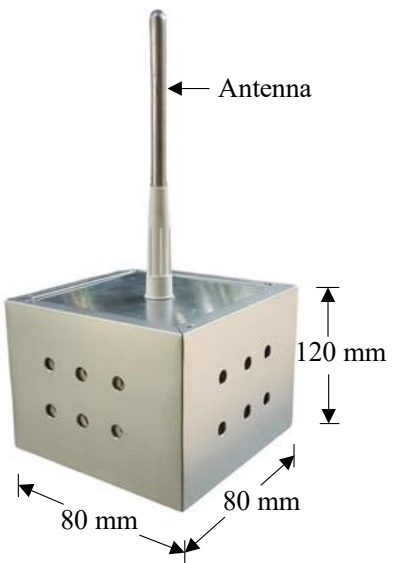

Fig. 10. The prototype of a self-powered heat detector based on thermoelectric generators with natural-rubber

\section{Conclusions}

This paper is presented a self-powered heat detector based on thermoelectrical energy harvesting technique. The device composes of thermoelectric device (TE) and the fins of heat sink were coated by natural-rubber which improved the temperature difference gap and stabilized the cold side of TE. The experimental results showed that the coated rubber was effective in suppressing and stabilizing the temperature and voltage, especially the temperature difference $(\Delta T)$ and the output voltage of F8T10 heat sink model achieved $39.9^{\circ} \mathrm{C}$ and $0.56 \mathrm{~V}$, respectively. This technique will potentially solve the power supply issue in fluctuated situations. Moreover, the rubber coating from rubber trees in Thailand would be a value chain added for the BCG economy.

\section{Acknowledgement}

This research was a partial supported by Science Park, Ministry of Higher Education, Science, Research and Innovation. Under the Developing Prototype of Products Project of University Business Incubator, Mahasarakham University.

\section{References}

[1] Alzhrani, M., Talib, A. B., Manarvi, I. (2017). Design and Development of a Hybrid Fire and Heat Detector Through Narrowing of Alternatives. 2017 9th IEEE-GCC Conference and Exhibition (GCCCE). doi: https://doi.org/10.1109/ieeegcc. 2017.8448120

[2] Ishiyama, T., Yamada, H. (2012). Effect of heat pipes to suppress heat leakage for thermoelectric generator of energy harvesting. 2012 International Conference on Renewable Energy Research and Applications (ICRERA). doi: https://doi.org/ 10.1109/icrera.2012.6477306 
[3] Cernaianu, M. O., Cirstea, C., Gontean, A. (2012). Thermoelectrical energy harvesting system: Modelling, simulation and implementation. 2012 10th International Symposium on Electronics and Telecommunications. doi: https://doi.org/10.1109/ isetc.2012.6408047

[4] Mahmud, K. H., Yudistirani, S. A., Ramadhan, A. I. (2017). Analysis Of Power Characteristics Of Model Thermoelectric Generator (TEG) Small Modular. International Journal of Scientific \& Technology Research, 6 (4), 161-167. Available at: https://www.ijstr.org/final-print/apr2017/Analysis-Of-Power-Characteristics-Of-Model-Thermoelectric-Generator-teg-SmallModular.pdf

[5] Wong, H.-P., Dahari, Z. (2015). Human body parts heat energy harvesting using thermoelectric module. 2015 IEEE Conference on Energy Conversion (CENCON). doi: https://doi.org/10.1109/cencon.2015.7409541

[6] Zhou, S.-Y., Zhuo, C., Min, Q., Li, E.-P. (2017). Graphene based thermoelectric energy harvesting in 3D ICs. 2017 IEEE Electrical Design of Advanced Packaging and Systems Symposium (EDAPS). doi: https://doi.org/10.1109/edaps.2017.8276959

[7] Oliveira, V. S., Miranda Camboim, M., Silva Guedes de Lima, B. A., Protasio de Souza, C., Baiocchi, O. (2020). A SolarRadiation-Powered Thermoelectric Energy Harvester based on Quasicrystal. 2020 IEEE International Instrumentation and Measurement Technology Conference (I2MTC). doi: https://doi.org/10.1109/i2mtc43012.2020.9128936

[8] Ilahi, T., Abid, M., Ilahi, T. (2015). Design and analysis of thermoelectric material based roof top energy harvesting system for Pakistan. 2015 Power Generation System and Renewable Energy Technologies (PGSRET). doi: https://doi.org/10.1109/ pgsret.2015.7312207

[9] Yadav, D., Azad, P. (2019). Experimental Analysis of Power Generation for Ultra-Low Power Wireless Sensor Nodes Using Various Coatings on Thermoelectric Energy Harvester. 2019 6th International Conference on Signal Processing and Integrated Networks (SPIN). doi: https://doi.org/10.1109/spin.2019.8711483

[10] Ağaçayak, A., Neşeli, S. (2017). The Impact of Different Electric Connection Types in Thermoelectric Generator Modules on Power. International Journal of Engineering Research \& Science (IJOER), 3 (12), 46-55. Available at: https://ijoer.com/ Paper-December-2017/IJOER-DEC-2017-10.pdf

[11] Shi, Y., Wang, Y., Deng, Y., Gao, H., Lin, Z., Zhu, W., Ye, H. (2014). A novel self-powered wireless temperature sensor based on thermoelectric generators. Energy Conversion and Management, 80, 110-116. doi: https://doi.org/10.1016/ j.enconman.2014.01.010

[12] Pathirana, W. P. M. R., Jayaweera, H. M. P. C., Muhtaroglu, A. (2015). Low input voltage and high step-up integrated regulator for thermoelectric energy harvesting. 5th International Conference on Energy Aware Computing Systems \& Applications. doi: https://doi.org/10.1109/iceac.2015.7352199

[13] Correa-Betanzo, C., Lopez-Perez, C., Rodriguez, A., Lopez-Nunez, A. (2019). Isolated DC-DC Converter for Thermoelectric Energy Harvesting Based on a Piezoelectric Transformer. 2019 IEEE Applied Power Electronics Conference and Exposition (APEC). doi: https://doi.org/10.1109/apec.2019.8721959

[14] Chen, J. J., Lien, Y. C., Kuo, C. L., Wu, W. J. (2015). Self-powered wireless temperature sensor with piezoelectric energy harvester fabricated with metal-MEMS process. 10th IEEE International Conference on Nano/Micro Engineered and Molecular Systems. doi: https://doi.org/10.1109/nems.2015.7147506

[15] Yap, Y. Z., Naayagi, R. T., Woo, W. L. (2016). Thermoelectric energy harvesting for mobile phone charging application. 2016 IEEE Region 10 Conference (TENCON). doi: https://doi.org/10.1109/tencon.2016.7848649

[16] He, Y., Ma, L.-X., Tang, Y.-Z., Wang, Z.-P., Li, W., Kukulka, D. (2015). Thermal Conductivity of Natural Rubber Using Molecular Dynamics Simulation. Journal of Nanoscience and Nanotechnology, 15 (4), 3244-3248. doi: https://doi.org/10.1166/ jnn.2015.9640

[17] Zhang, X., Yi, J., Yin, Y., Song, Y., Xiong, C. (2021). Thermal conductivity and electrical insulation properties of h-BN@PDA/ silicone rubber composites. Diamond and Related Materials, 117, 108485. doi: https://doi.org/10.1016/j.diamond.2021.108485

How to cite: Prathepha, K., Sa-ngiamvibool, W. (2021). The investigation of natural-rubber for improving self-powered heat detector based on thermoelectric generators. EUREKA: Physics and Engineering, 6, 65-73. doi: https://doi.org/10.21303/ 2461-4262.2021.002117 